\title{
INFLUENCE OF GRINDING CONDITIONS ON SURFACE QUALITY AND ACCURACY WHEN A TOOL GRINDER IS USED
}

\author{
Jindřich Farský, Miroslav Zetek, Tomáš Bakša, Pavel Adámek
}
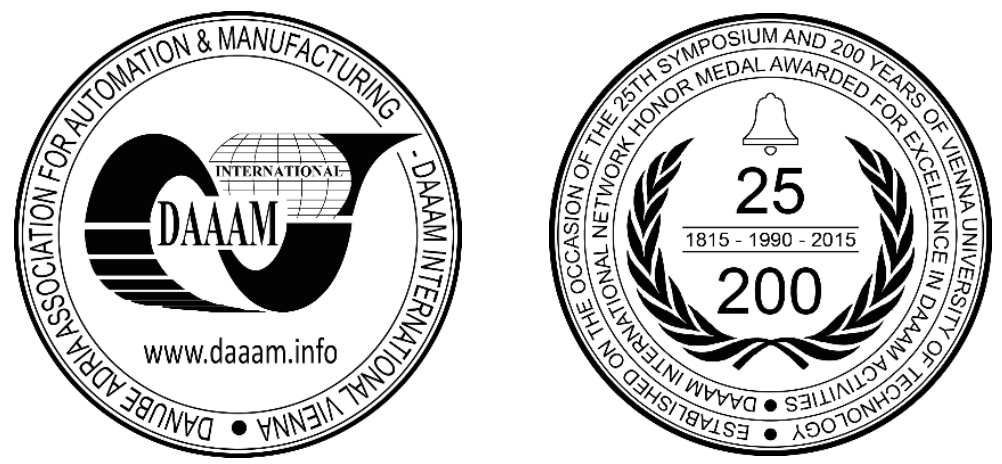

This Publication has to be referred as: Farsky, J[indrich]; Zetek, M[iroslav]; Baksa, T[omas] \& Adamek, P[avel] (2017). Influence of Grinding Conditions on Surface Quality and Accuracy when a Tool Grinder is Used, Proceedings of the 28th DAAAM International Symposium, pp.0930-0936, B. Katalinic (Ed.), Published by DAAAM International, ISBN 978-3-902734-11-2, ISSN 1726-9679, Vienna, Austria

DOI: $10.2507 / 28$ th.daaam.proceedings.129

\begin{abstract}
This work deals with the investigation of the influence of grinding conditions on the surface quality and accuracy of dimensions when grinding complex shaped surfaces on an ANCA MX7 5-axis tool grinder. The upper part of a knee implant was selected as a representative example of a complex shaped surface. NC programs in NX CAM software with a postprocessor from ANCA were created for this work. The aim of this work was to design and implement an experiment to study the influence of cutting conditions during grinding. To carry out this experiment it was necessary to design the technology for grinding the knee implant, create an NC program for grinding, and construct a clamp for the knee implant.
\end{abstract}

Keywords: Grinding; 5-axis tool grinder; surface quality; accuracy; grinding conditions; NX

\section{Introduction}

It is necessary to achieve accurate dimensions and high surface quality on components with complex shapes. Therefore attention must be paid to grinding complex shaped surfaces on multi axis-grinding machines. One of these grinders is the ANCA MX7 tool-grinding machine, on which it is possible to grind complex shaped surfaces. Because tool-grinding machines are mainly designed for grinding rotary cutting tools or general rotary components, the use of these grinders has many pitfalls for grinding components which have complex shapes.

One of the problems is creating NC data using CAM software with a special postprocessor. Other issues are designing and creating special clamping fixtures for these complex shaped surfaces, choosing the right grinding strategy, selecting the right cutting conditions, etc.

As already mentioned, accurate dimensions and high surface quality of components with complex shaped surfaces are required. [1] These two conditions are most affected by the selection of the correct grinding conditions. By changing one of these parameters we can achieve different surface quality and different dimensions, because changing the grinding conditions influences both the surface quality and the temperature at the cutting point. These influences are shown in Fig. 1., 2., 3., 4 . 


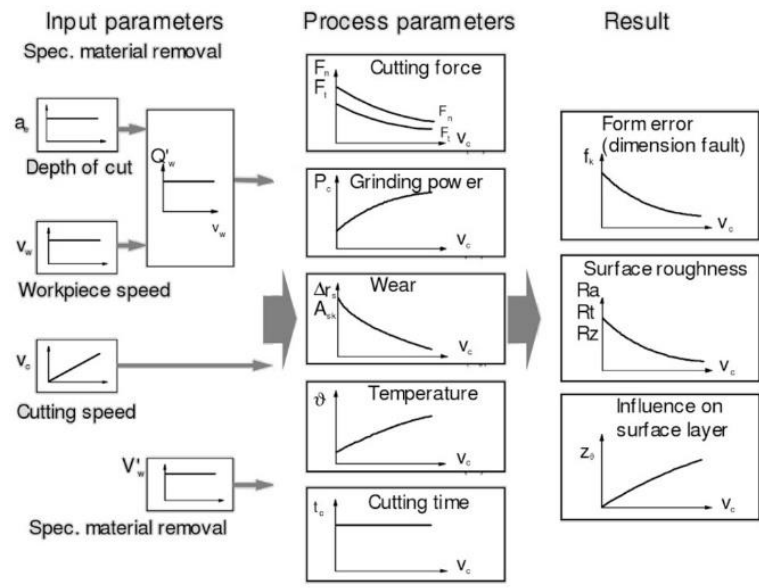

Fig. 1. The influence of cutting speed on process parameters and output [2]

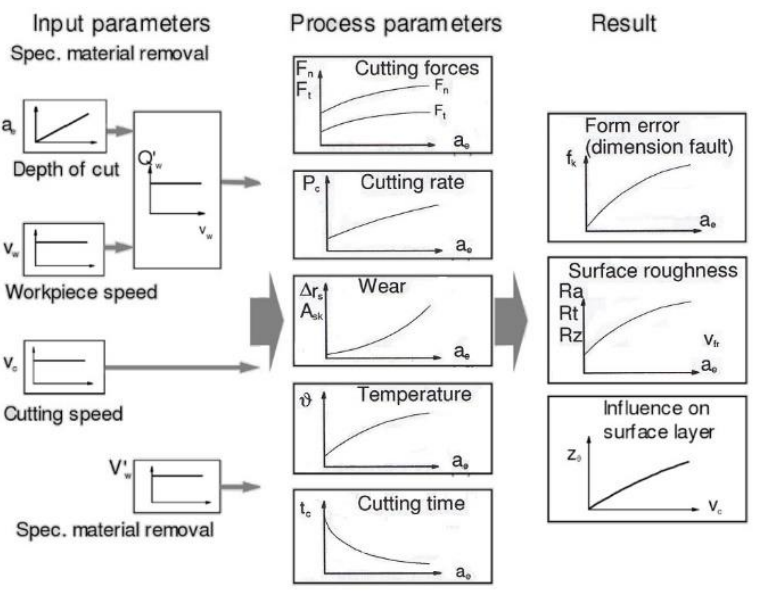

Fig. 2. The influence on feed rate and depth of cut on process parameters and output [2]

The aim of this work is to investigate the influence of grinding conditions on the surface quality and accuracy of dimensions when grinding complex shaped surfaces on the upper part of a knee implant which is not intended for medical purposes. Surface quality in this work means surface roughness with parameters $\mathrm{Ra}, \mathrm{Rq}$ and $\mathrm{Rz}$, and accuracy dimensions are derived from the amount of deviation away from the surface of the component. To minimize the errors in the experiment caused by wear of the grinding wheel, the wear of the grinding wheel was measured after each grinding and the diameter correction was entered in the grinder control software. [5], [6]

\section{The selected component}

The component selected for this experiment was the upper part of a knee implant, shown in Fig. 3. The semi-finished product for this experiment was printed on a 3D printer using martensitic steel, which is designated by the producer as EOS MaragingSteel MS1 to DIN classification X3NiCoMoTi 18-9-5. This material is used in cutting tools and high performance industrial and engineering parts. It is characterized by a hardness of around $35 \mathrm{HRC}$ in its natural state and after age hardening its hardness rises to 50 - 56 HRC. [7] [8]
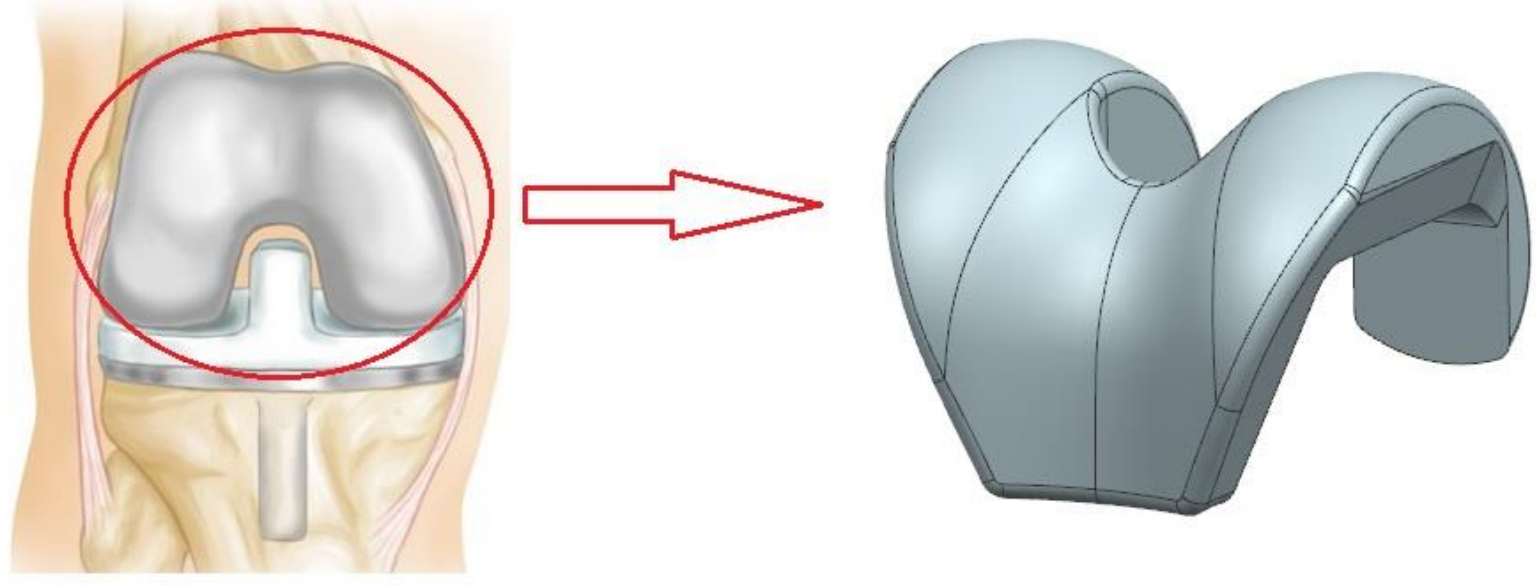

Fig. 3. Knee implant [8]

\section{Introducing the experiment}

As has already been mentioned, the aim of this work is to study the influence of grinding conditions on surface quality and the accuracy of dimensions. We needed to limit the potentially very large scope of the experiment. These limitations were in terms of the equipment and the selected input parameters. The tool grinding machine ANCA MX7 is limited by two things. The first limit is the maximum revolutions on the spindle, which is $10000 \mathrm{rpm}$. The second limit of the machine is the spindle clamping system, which only allows the clamping of cylindrical components. The grinding wheel 1FF1 CBN was the next limit, due to its maximum grinding speed of $63 \mathrm{~m} \cdot \mathrm{s}^{-1}$, and its composition, which is marked as B64C75B54. The limits from the input parameters are based on research from other articles that show which grinding parameters most influence the quality and dimensions of the ground surfaces. In order to correctly design the experiment, it is necessary to select those grinding parameters which most influence the evaluated parameters. Three grinding 
parameters are selected: grinding speed, axial feed and feed rate. Another variable parameter is the tilt of the tool spindle by $30^{\circ}$ degrees to test whether tilting has an effect on the parameters being evaluated. The axial feed in this case is set by the maximum scallop height, because CAM software NX only allows set up of this parameter, from which can be calculated the approximate rate of the axial feed. The equation for calculating axial feed from maximum scallop height is

$$
\begin{aligned}
& s c=R-\sqrt{R^{2}-\left(\frac{a_{p}}{2}\right)^{2}} \\
& a_{p}=2 \cdot \sqrt{R^{2}-(R-s c)^{2}}
\end{aligned}
$$

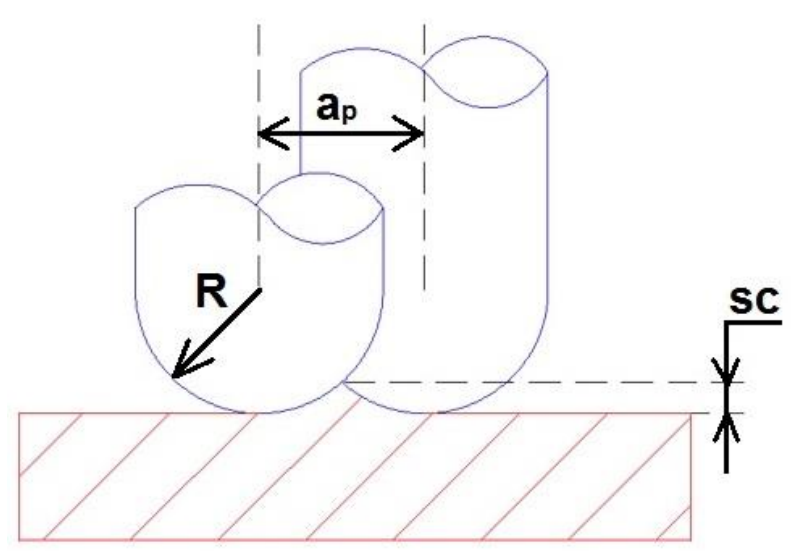

Fig. 4. Diagram of maximum scallop height [9]

The cutting speed is limited by the maximum spindle speed, which is $10000 \mathrm{rpm}$, and the maximum cutting speed of the grinding wheel, which is $63 \mathrm{~m} / \mathrm{s}$. The value of the feed speed was selected from the lower values, because this is the first grinding of this type on the ANCA MX7 grinder using NX CAM software with the new postprocessor. Parameters for the experiments are given in the following tables.

Table 1 shows the values for preparation of the component for the main experiment. The preparation grinding with parameter values HR00 was performed several times until the knee implant surface was ready for the experiment. Values in the last operation in the pre-grinding were the same as the first value in the experiment so as not to affect the experiment.

Table 2 shows the values for individual experiments. Parameter " $s c$ " is the maximum scallop height and the next column gives the approximate values of axial feed which are calculated from the formula.

\begin{tabular}{c|cccccc}
\multicolumn{1}{c}{} & $s c[\mathrm{~mm}]$ & $a_{p}[\mathrm{~mm}]$ & $v_{c}\left[\mathrm{~m}_{\mathrm{s}}^{-1}\right]$ & $v_{f}\left[\mathrm{~mm}_{\mathrm{min}} \mathrm{min}^{-1}\right]$ & $a_{e}[\mathrm{~mm}]$ & Distance [mm] \\
\hline HROO & 0.1 & 1.536 & 20 & 50 & 0.1 & From 0 to -1 \\
HRO1 & 0.005 & 0.346 & 30 & 150 & 0.05 & -1.05
\end{tabular}

Table 1. Preparatory grinding

\begin{tabular}{l|cccccc}
\multicolumn{1}{l}{} & $s c[\mathrm{~mm}]$ & $a_{p}[\mathrm{~mm}]$ & $v_{c}\left[\mathrm{~m}_{\mathrm{s}}^{-1}\right]$ & $v_{f}\left[\mathrm{~mm}_{\mathrm{min}} \mathrm{mi}^{-1}\right]$ & $a_{e}[\mathrm{~mm}]$ & Distance $[\mathrm{mm}]$ \\
\hline EXP01 & 0.005 & 0.346 & 30 & 150 & 0.05 & -1.10 \\
EXP02 & 0.005 & 0.346 & 40 & 150 & 0.05 & -1.15 \\
EXP03 & 0.005 & 0.346 & 30 & 200 & 0.05 & -1.20 \\
EXP04 & 0.005 & 0.346 & 40 & 200 & 0.05 & -1.25 \\
EXP05 & 0.001 & 0.155 & 30 & 150 & 0.05 & -1.30 \\
EXP06 & 0.001 & 0.155 & 40 & 150 & 0.05 & -1.35 \\
EXP07 & 0.001 & 0.155 & 30 & 200 & 0.05 & -1.40 \\
EXP08 & 0.001 & 0.155 & 40 & 200 & 0.05 & -1.45
\end{tabular}

Table 2. The main experiments

\section{Preparation of experiment}

Before the experiment it is necessary to design the grinding technology so that the experiment is not affected by errors which could affect the results. The following section gives some basic information about the design of the grinding technology, construction of the clamping jig, creation of NC data in the NX CAM software and checking the NC data on the grinder which was generated from the NX software. 


\subsection{Design of the grinding technology}

Designing the grinding technology includes the definition of the surface which is to be ground, the grinding strategy, definition of the grinding wheel, and basic kinematics of the grinding machine. This design is very important, because errors may be introduced in to the experiment which affect the evaluated parameters. First of all it is necessary to define which surfaces are to be ground. Fig. 5. highlights the surfaces to be ground in orange. The second step is to choose a grinding strategy. In this case a "zig-zag" strategy is selected, where the grinding wheel moves backwards and forwards, and moves the axial feed value after each step. A radius-grinding wheel (Fig. 6) was selected to grind the surface, which has a basic designation of 1FF1 $100 \times 6 \times 20$ with a maximum cutting speed is $63 \mathrm{~m} / \mathrm{s}$. The cutting speed is limited by the kinematics of the grinding machine, in particular the maximum revolutions per minute on the spindle of the machine, of $10000 \mathrm{rpm}$. The basic kinematics of the ANCA MX7 tool grinder is shown in Fig. 7.



Fig. 5. Highlighted surface to be ground

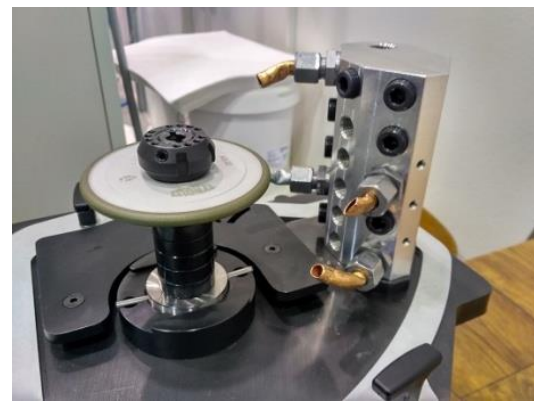

Fig. 6. The grinding wheel

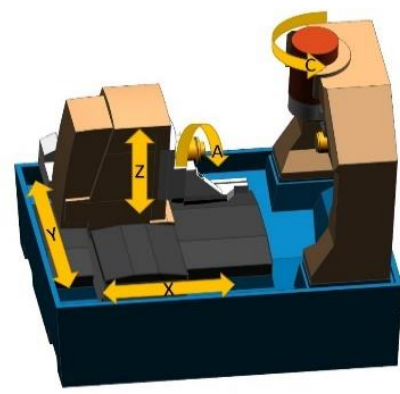

Fig. 7. Kinematics of ANCA MX7

\subsection{The clamp}

In order to grind the knee implant, it was necessary to design and manufacture a clamp, as the clamping collet on the machine only allows cylindrical components to be clamped. The clamp (Fig. 8) is divided into three main sections, the clamping part for the collet, the clamping part for the knee-implant and the reference part. There is a flat section on the reference part which is for setting the zero position axis A on the grinder and to ensure the repeatability of clamping in the same position both on the grinder and on the measuring machine. This surface is also parallel to the clamping surface for the knee-implant, which is in the middle part of the clamp.

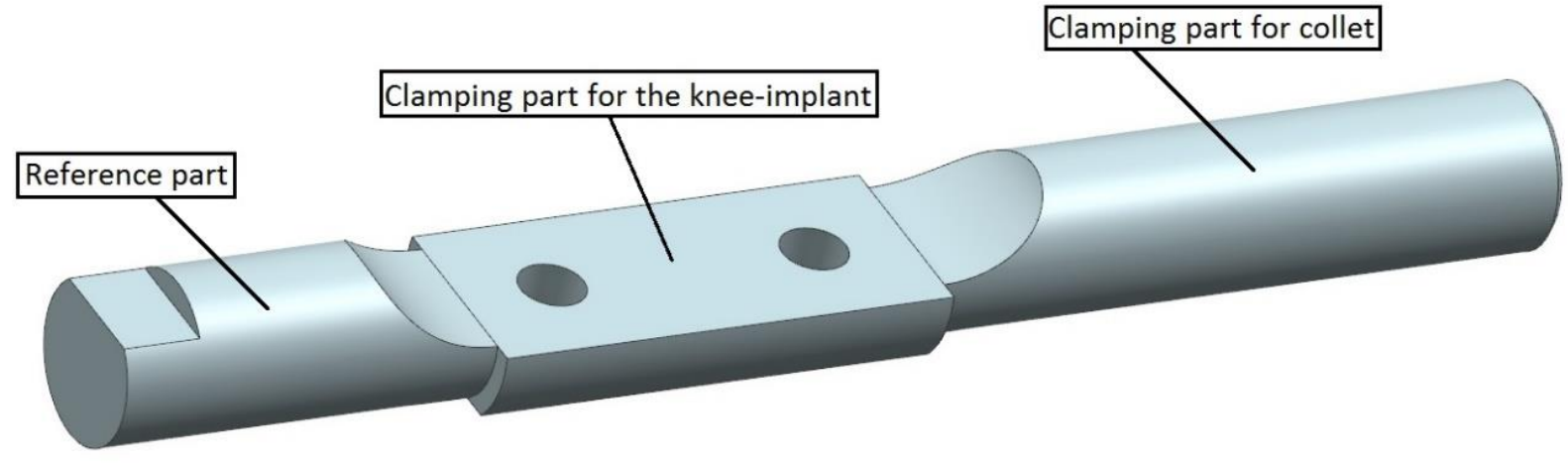

Fig. 8. Clamp for the knee implant

\subsection{Creating NC data in NX software}

To carry out the experiment it was necessary to create the NC data in NX software. This software also provides collision checking between the machine, the grinding wheel, the component and the clamp. This collision checking discovered two collisions between the clamp and the spindle. As mentioned earlier, one variable is the tilting of the tool spindle by $30^{\circ}$ degrees. This tilt is located in the back half of the knee-implant. Therefore the grinding technology is divided into two parts.

The first part is grinding without tilting the spindle and is located on the front half of the knee-implant (Fig. 9). The second part, which is located on the back half the knee-implant, is performed with the spindle tilted by $30^{\circ}$ degrees (Fig. 10). This spindle tilt prevents collision between the spindle and the clamp, as shown in Fig. 11. After creating the grinding technology in NX software, it is necessary to generate the NC data in the special postprocessor which was designed for the ANCA MX7 tool grinder. 


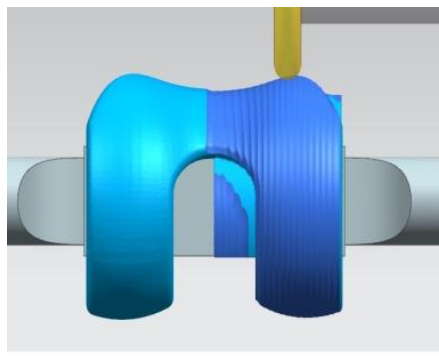

Fig. 9. Grinding without tilting the spindle

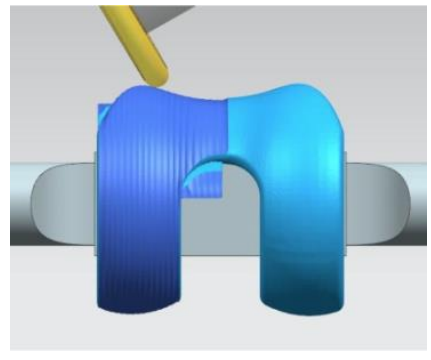

Fig. 10. Grinding with spindle tilted by $30^{\circ}$ degrees

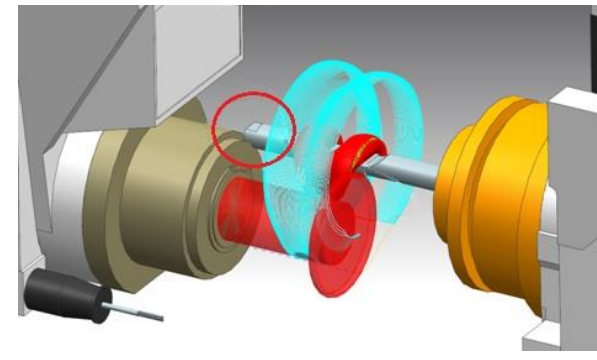

Fig. 11. Collision between spindle and clamp

\section{Rating experimental results}

As mentioned in the introduction, this work deals with the influence of the cutting conditions on the surface quality and accuracy of dimensions. Parameters of surface roughness $\mathrm{Ra}, \mathrm{Rq}$ and $\mathrm{Rz}$ are selected for evaluation of surface quality. The accuracy of dimensions after grinding were evaluated according to the size of the deviations from the desired dimensions. The size of the wear of the grinding wheel was also monitored, which was subsequently corrected in the control software on the grinder.

\subsection{Grinding wheel wear}

To minimize the errors in the experiment caused by wear of the grinding wheel, the wear of grinding wheel was measured after each grinding, because grinding releases worn abrasive grains from the binder of the grinding wheel. Because a new grinding wheel was used, this wear is considerable at the start, because the abrasive grains are not so tightly bound to the binder in the surface layer. The wear process is shown in Fig. 12, and on the left the high wear of the grinding wheel can be seen, which was recorded during the roughing process. This wear was corrected using the average correction of the grinding wheel in the control software. In the experiment, the wear was minimal and reached values of $0.01 \mathrm{~mm}$ per diameter. The wear of the grinding wheel during the experiment is shown on the right side of the graph.

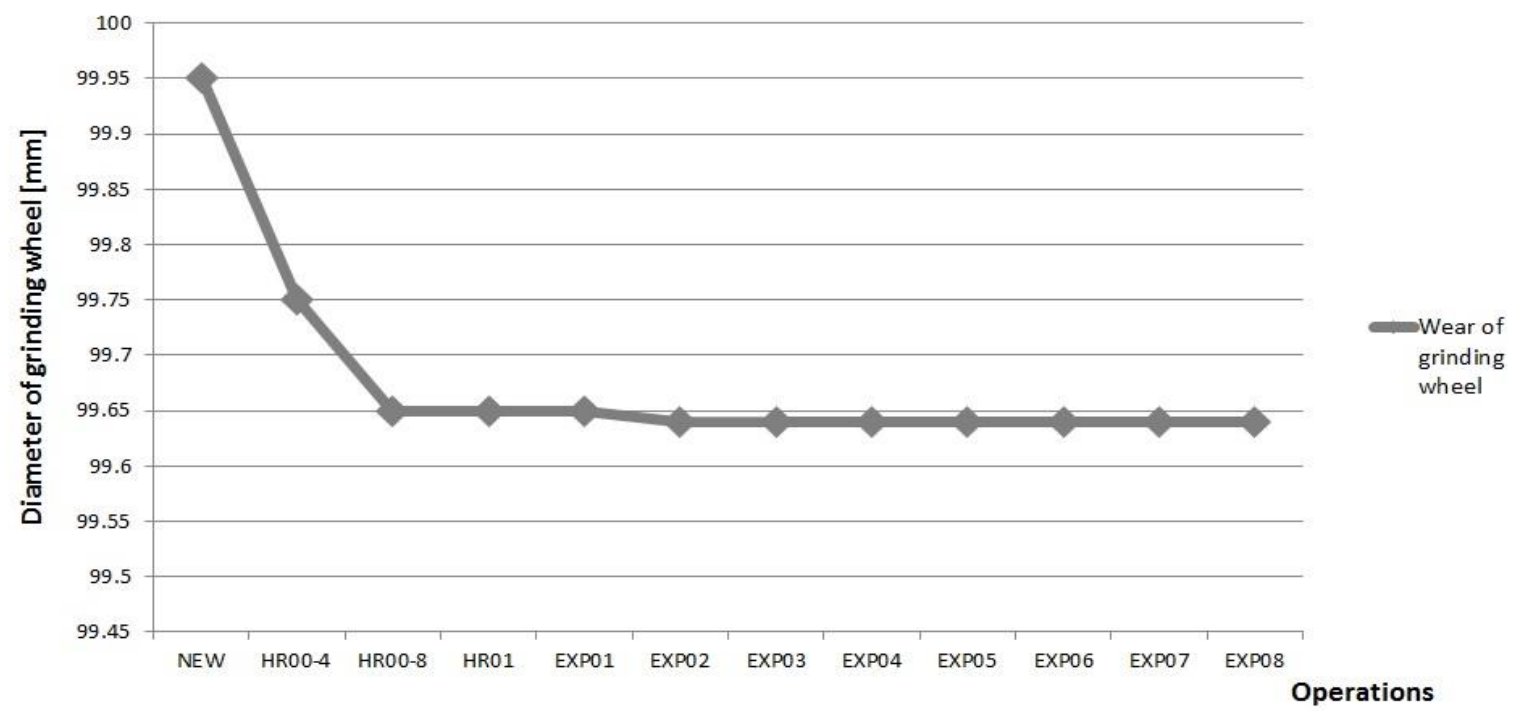

Fig. 12. Wear of the grinding wheel

\subsection{Surface roughness}

Roughness was measured as it is an excellent indicator of surface quality. The change in the surface roughness is evaluated in relation to the change in the cutting conditions and on the change of the tilt of the spindle. For each experiment at least ten surface roughness measurements were made on eight sections of the component. The average value of the surface roughness for each experiment was calculated from the measured values. These values are compared with each other depending on the input parameters. The greatest influence on the surface roughness was the axial feed value, which is here called the maximum scallop height "sc". The second value which influences the surface roughness is the cutting speed. The third value is the feed rate. These values are shown in Fig. 13. The tilt of the spindle also influences the surface roughness, but only up to a certain value of maximum scallop height. As shown in Fig. 14, the difference of values for sc $=0.005$ is $0.35 \mu \mathrm{m}$, but for $\mathrm{sc}=0.001$ it is $0.025 \mu \mathrm{m}$. 


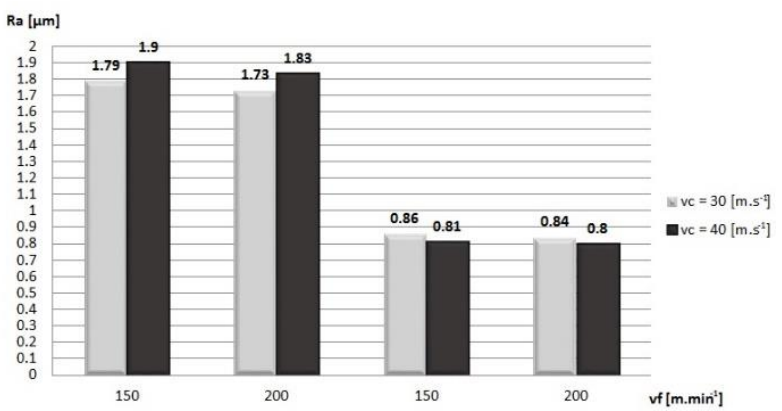

Fig. 13. Surface roughness in relation to cutting conditions

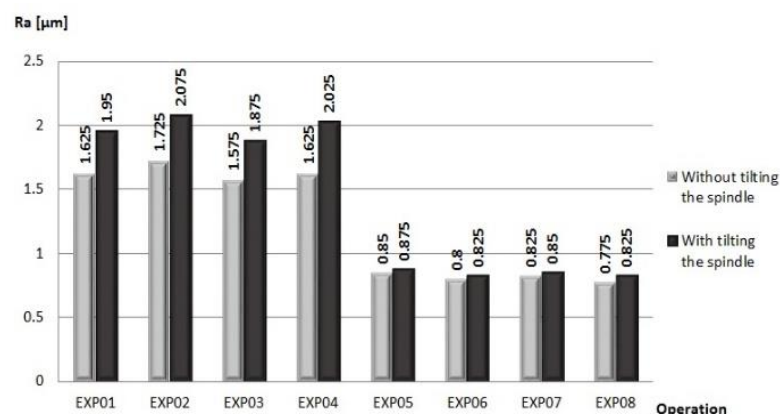

Fig. 14. Surface roughness in relation to spindle tilt

\subsection{Accuracy of dimensions}

The next parameter which determines the accuracy of the dimensions is the value of the deviation from the desired dimension. This deviation was measured on a coordinate measuring machine using the contact method. After each experiment the component was measured at eight sections and at least ten points were measured in each section. The average value of the deviance in each section is calculated from the measured values. Subsequently, the mean variance for each experiment is calculated from these values. These values are included in the graph, where the average deviance from the desired dimension is $0.0067 \mathrm{~mm}$ without tilting the spindle (Fig. 15) and $0.2476 \mathrm{~mm}$ with tilting the spindle (Fig. 16). Accuracy achieved here does not match the required accuracy, and therefore it was necessary to verify the accuracy of the displacement of the tracks of the experiments which have the same input variables. These are the last preparatory roughing "HR01" and the first experimental grinding "EXP01", because these grindings have the same input variables. From these values were calculated deviation displacements of the tracks of the grinding and these deviations are shown in Fig. 17, where the average deviation displacement of the track is $0.003 \mathrm{~mm}$ without tilting the spindle and $0.011 \mathrm{~mm}$ with tilting the spindle. Only the value without tilting can be considered correct. These geometrical inaccuracies may be caused by changes to the grinding wheel profile by wear, or errors in the conversion of $3 \mathrm{D}$ correction in the postprocessor.

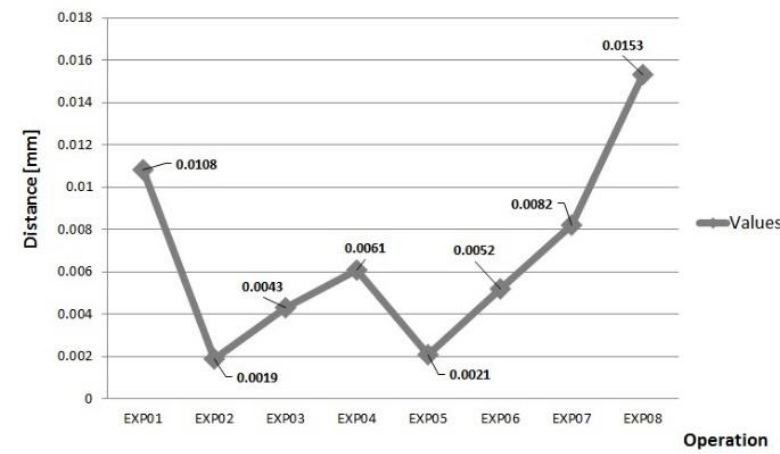

Fig. 15. Accuracy of dimensions without tilting

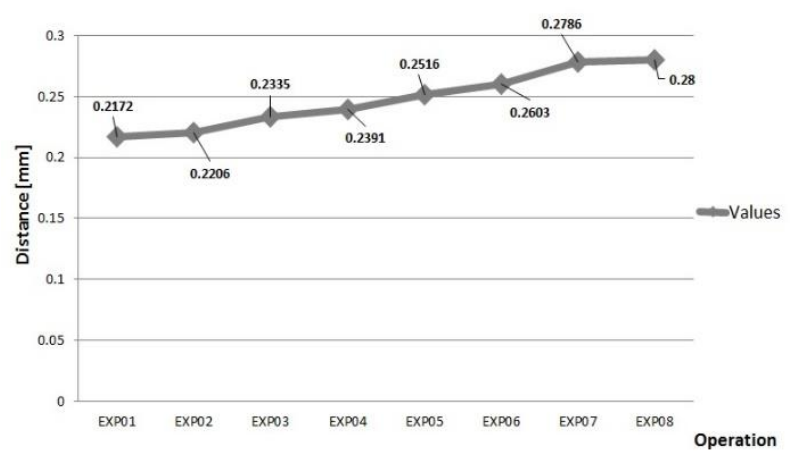

Fig. 16. Accuracy of dimensions with tilting

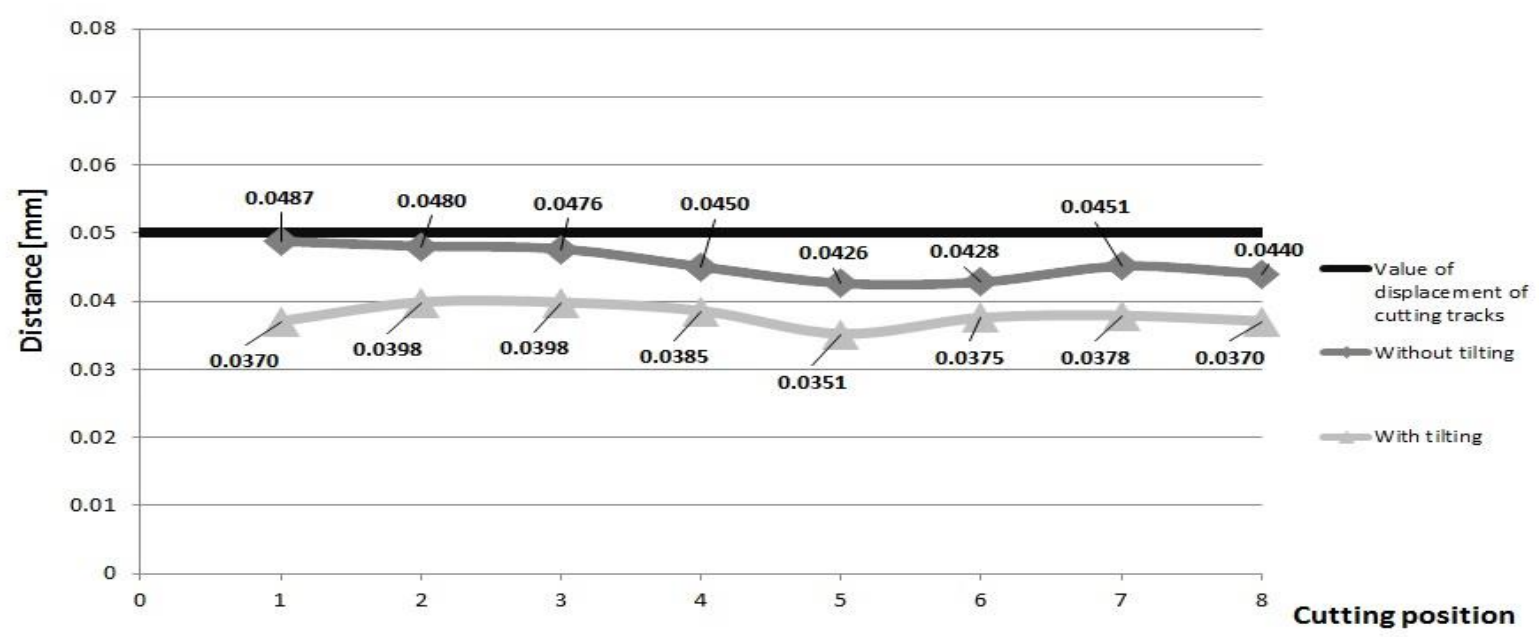

Fig. 17. Geometric accuracy of displacement of cutting tracks 


\section{Conclusion}

The issue of grinding complex shaped surfaces is very complicated and extensive due to the large number of changes that affect the resulting accuracy and surface quality. Therefore, this work demonstrates only parts of this issue, because the main idea of this work is the investigation of the influence of the cutting conditions on the surface quality and the accuracy of dimensions. This investigation proved that the required roughness parameters can be achieved by using the right combination of cutting parameters, axial feed rate and cutting speed. The biggest problem for the accuracy of dimensions is the tilting of the spindle, because the tilting of the spindle changes the cutting point and this change leads to the deterioration of the accuracy of dimensions by uneven wear of the grinding wheel. This problem can been removed by keeping the profile curve of the grinding wheel radius.

Because this is a very extensive issue, it is necessary to focus more on the preparation of the experiments, and above all, on the wear of the grinding wheel, dressing the grinding wheel and the corrections of the tools. Also it is necessary to pay attention to the manufacturing accuracy of the clamp, because inaccuracies from manufacturing the clamp can introduce errors into the experiments.

This experiment provides the basis for future research dealing with grinding complex shaped surfaces. This experiment shows the influence of the grinding conditions on the surface quality and accuracy of dimensions on complex shaped surfaces. From the results, it is evident that it is necessary to focus in the future on the accuracy of dimensions when the spindle is tilted. Therefore further research will be focus on the accuracy of dimensions during grinding with a tilted spindle and during continuous 5-axis grinding. This article also serves as a default article for future research in this field.

\section{Acknowledgments}

The present contribution has been prepared under project LO1502 'Development of the Regional Technological Institute' under the auspices of the National Sustainability Programme I of the Ministry of Education of the Czech Republic aimed at supporting research, experimental development and innovation.

\section{References}

[1] Denkena, B.; Grove, T. \& Lucas, H. (2016). Influences of grinding with Toric CBN grinding tools on surface and subsurface of 1.3344PM steel. Journal of Materials Processing Technology, vol. 229, pp. 541-548, ISSN: 09240136.

[2] Klocke, F. (2009). Manufacturing Processes 2: Grinding, Honing, Lapping. Springer Science \& Business Media, ISBN: 978-3-540-92259-9.

[3] Davim, J. P. (2011). Modern Machining Technology: A Practical Guide. Elsevier, ISBN: 978-0-85709-494-0.

[4] Rokyta, L. (2011). Testing of grinding wheel for tools manufacturing. Proceedings of the 22nd International DAAAM Symposium, Volume 22, No. 1, pp 1137-1138, B. Katalinic (Ed.), Published by DAAAM International ISBN 978-3-901509-83-4, ISSN 1726-9679, Vienna, Austria.

[5] Novak, M. (2012). Surfaces with high precision of roughness after grinding. Manufacturing Technology, vol. 12, pp. 66-70, Published by Institute of Technology and Production Management University of J.E. Purkyne ISSN 1213-2489, Usti nad Labem, Europe, Czech Republic.

[6] LUKOVICS, I. (2006) 'HIGH-SPEED GRINDING OF TOOLS AND TOOLING'. A shortened version of habilitation work. Brno 2016. ISSN 1213-418X, ISBN 80-214-3305-1. [cit. 2017-08-20]. Available: http://www.vutium.vutbr.cz/tituly/pdf/ukazka/80-214-3305-1.pdf.

[7] MaragingSteel MS1 Material data sheet, [Accessed: 2017-08-21] @ 2007 EOS GmbH - Electro Optical Systems. Available: https://www.axisproto.com/pdf/MaragingSteel_MS1_Material_data_sheet_07-07_en.pdf

[8] 'Unicompartmental Knee Replacement-OrthoInfo - AAOS'. [Accessed: 2017-08-21]. Copyright (C1995-2017 by the American Academy of Orthopaedic Surgeons. Available: http://orthoinfo.aaos.org/topic.cfm?topic=a00585.

[9] Router-CIM 2016, Constant Scallop Height. [Accessed: 2017-08-21]. (C) 2016 CIM-Tech.com, Inc. Available: http://www.cimtechsoftware.com/RouterCIM_Online_Help/constant_scallop_height.htm. 